\title{
ORIGEM E FORMAÇÃO DAS DOMÁCIAS EM COFFEA $L$.
}

\author{
Myrthes Apparecida Adâmoli de Barros
}

E. A. S. «Luiz de Queiroz»

* Recebido para publicação em 4/8/60. 


\section{INTRODUÇÃO}

Uma vez concluido o estudo morfológico e anatômico das domácias que ocorrem nas variedades e formas de Coffea arabica $L$. (Adâmoli de Barros, 1955), decidimos continuar as observações nesse setor, escolhendo inicialmente, como era óbvio, a importante família Rubiaceae, ricamente representada em nossa flora por numerosas espécies.

Para a consecução dêsse objetivo, conseguimos reunir abundante material, constante de fôlhas, em sua maioria de herbário, num total de 622 espécies. Os resultados dêsses meticulosos estudos serão publicados, oportunamente, pelos Anais da Escola Superior de Agricultura "Luiz de Queiroz".

Diante das excelentes perspectivas que a nossa vegetação oferece ao estudo das domácias, desejamos alargar nosso campo de observação, estendendo-o ao maior número de famílias, consoante plano já elaborado, o que nos permitirá fazer um levantamento das espécies portadoras dessas interessantes estruturas, bem como estudá-las sob os aspectos morfológico, anatômico, fisiológico, biológico e taxônomico.

Neste trabalho, focalizamos o problema da origem das domácias, pois que, até o presente, os autores não chegaram a uma definição quanto à natureza e à função das domácias, existindo a respeito duas hipóteses : a primeira considera as domácias como sendo provocadas por ácaros ou por insétos; a segunda encara as domácias como um caráter morfológico, desenvolvendo-se, portanto, com o crescimento da fôlha.

Escolhemos, para as nossas investigações preliminares, as principais variedades de Coffea arabica $L$., portadoras de domácias, e as conclusões a que chegamos constam dêste trabalho.

\section{REVISÃO DA LITERATURA}

Consoante se despreende das pesquisas bibliográficás sôbre a origem das domácias, as opiniões a êsse respeito são divergentes como se pode verificar pelas citações que se seguem :

LUNDSTRÖEM, citado por DU RIETZ (1930), julga que as domácias foram, originàriamente, produzidas por acarídeos, tornando-se, posteriormente, estáveis e hereditárias. A teoria de LUNDSTRÖEM, comenta DU RIETZ, foi fruto de seu tempo e aceita pelos autores da época. Entretanto, graves dúvidas foram levantadas por A. G. HAMILTON (1896), que após investigar as 
domácias em um grande número de plantas da Austrália achou que o problema necessitava de uma completa revisão. Finalizando, conclui o citado autor: poucos botânicos dos nossos dias acreditam na teoria da simbiose mutualista de LUNDSTRÖEM.

ZIMMERMANN, mencionado por J. SAMPAIO (1927), considera as domácias como uma formação ainda não definida quanto à sua natureza.

CHEVALIER (1941), estudando as domácias das Juglandáceas, afirma que "frequentemente as domácias existem sem que se descubram sequer sinais de ácaros nas fôlhas. É certo, pois, que seu desenvolvimento não é provocado por irritação, líquido ou virus inoculado por qualquer organismo vivo, conforme se observa no caso das cecídeas. Estes órgãos têm real valôr sistemático, o caráter é hereditário e próprio de certas espécies e de determinados gêneros".

\section{MATERIAL E METODO}

O material para o presente estudo constou principalmente de ramos e sementes de cafeeiros, provenientes das coleções vivas do Instituto Agronômico de Campinas, cedidos gentilmente pelo Dr. Alcides Carvalho.

As fôlhas novas e adultas dos ramos ortótropos e plagiótropos de algumas variedades de Coffea arabica $L$. foram examinadas, ao binocular.

Para verificar se as domácias constituiam um caráter morfológico, investigamos sua presença nas fôlhas ainda nas gêmas. Para tanto, lançamos mão de gêmas laterais e apicais das variedades estudadas e que foram fixadas e incluidas em parafina para obtenção de cortes anatômicos seriados, segundo o método preconizado por CHAMBERLAIN (1932).

A fixação da ponta dos ramos foi feita com o FAA, que é um dos fixadores mais indicados para gêmas e ápices vegetativos.

Os cortes transversais e longitudinais foram feitos com a espessura de 18 a 20 micra e óbtidos com o micrótomo Spencer modêlo 820 .

$\mathrm{Na}$ coloração, empregamos o corante duplo violeta-cristal e eritrosina, em óleo de cravo, consoante técnica descrita por JONHANSEN (1940).

A montagem permanente das estruturas foi feita com Bálsamo-do-Canadá.

Examinamos também fôlhas bem novas de Coffea arabica $L$. 
var. semperflorens nov. var. de dois tamanhos: $3 \times 7 \mathrm{~mm} \mathrm{e} 4 \times 8 \mathrm{~mm}$, das quais obtivemos cortes histológicos para exame ao microscópio.

Para certificarmo-nos se as domácias seriam provocadas por ácaros ou por insétos, colocamos no germinador elétrico "Jacóbius", sôbre papel de filtro umedecido com água destilada, sementes de Coffea arabica L. var. bourbon (B. Rodr.) Choussy, de germinação precóce. Coberto o germinador com placas de vidro, as sementes ficaram à temperatura de $36^{\circ} \mathrm{C}$, durante 30 dias, findo os quais começaram a germinar.

Dias depois, quando as radiculas se apresentavam bem desenvolvidas, transferimos os "seedlings" para vasos de Erlenmeyer com solução nutritiva de Hoagland. Tivemos o cuidado de pintar o interior dos vasos para escurecê-los, evitando assim a proliferação de algas na solução nutritiva. A seguir, cobrimos os vasos com uma campânula de vidro, para isolar os "seedlings", cujos cotilédones começavam a se expandir, do contato dos insetos e ácaros. A aeração da solução era feita todos os dias com uma pipeta.

Fizemos uma segunda prova nos moldes da piimeira, desta vez com sementes do Coffea arabica L. var. caturra, nov. var., após prévia desinfeção com "Arazan". A semeadura foi feita em vasos de barro, cobertos com placas de vidro, e os "seedlings" cultivados em solução nutritiva de Hoagland, em vasos de Erlenmeyer, tomando-se tôdas as precauções assinaladas pa:a a variedade "bourbon".

\section{DISCUSSÃO DOS RESULTADOS}

Dividiremos a análise dos resultados em duas partes. A primeira, referente ao exame minucioso dos cotilédones e das duas fôlhas primordiais que permaneceram sob campânula e a segunda relacionada com a interpretação das estruturas anatômicas.

a) Provocada por ácaro ou por inséto.

Consistiu no exame minucioso, feito ao binocular com grande aumento, dos cotilédones e das fôlhas primordiais das plantinhas que cresceram sob campânula de vidro e pudemos verificar que possuiam domácias, embora com a completa ausência de ácaros, larvas e ovos no interior da estrutura, bem como na superfície foliar. Comprova-se pois, que as domácias não são produzidas por ácaros ou insétos como se pensava. 


\section{b) Caräter morfológico.}

Investigamos a presença das domácias nas fôlhas ainda nas gêmas. Das séries completas de cortes cujas estruturas foram acuradamente examinadas ao microscópio, verificamos que nesse estágio as fôlhas não revelam indício algum de domácia.

Isto posto, estendemos nossas observações às fôlhas bem novas de dois tamanhos: $3 \times 7 \mathrm{~mm}$ e $4 \times 8 \mathrm{~mm}$.

As fôlhas menores nada revelaram quando examinadas ao binocular, ao passo que as maiores, mostravam apenas uma pequena depressão puntiforme na face inferior do limbo e no local das domácias, ou seja na axila da nervura principal com a secundária.

De ambos os tipos de fôlhas, examinamos as séries completas de cortes histológicos e verificamos, ao microscópio, que tanto num caso (fôlhas novas sem esboço) como noutro (fôlhas com pequenas depressões axilares), as domácias já se encontravam esboçadas, constituindo êsse aspecto a primeira fase de sua diferenciação. Neste estágio do desenvolvimento foliar, a domácia apresenta-se como um envaginamento da epiderme, em forma de fenda, localizada bem na junção da nervura secundária com a principal.

Devemos considerar que a nervura principal, nas estruturas examinadas, mostra-se bem saliente na face inferior do limbo, com a forma de um semicírculo e que a secundária, conquanto também forme um arco, é bem menor. Pois bem, a domácia, nesta fase, é precisamente a fenda separada pelos dois arcos, situando-se, por conseguinte, na axila do ângulo que as nervuras formam.

À volta dêsse envaginamento, internamente, existem de 3 a 4 camadas de células pequenas, que se alternam entre si, de forma quadrangular, bem justapostas e com núcleo bem visível. Essas células diferem das restantes do mesofilo pelas características apontadas e se circunscrevem apenas à zona do envaginamento.

A epiderme que participa da domácia revela-se ligeiramente modificada. Suas células, à medida que se afastam da entrada (bôca), vão se tornando mais estreitas e um pouco mais altas, com os cantos (ângulos) arredondados, suas membranas são mais delgadas e menos cutinizadas.

Fica por conseguinte, afastada a hipótese de ser a domácia causada por insétos ou ácaros. Trata-se de um caráter morfológico de gênero uma vez que sua ocorrência também foi assinalada em 76 espécies de Coffea, de acôrdo com CHEVALIER (1947) além de existir em Psychotria e Ixora, segundo A. J. SAMPAIO (1947) e em 88 espécies de Rubiáceas observadas por nós (ADAMOLI DE BARROS, 1959), e distribuidas dentro de 35 gêneros. 


\section{RESUMO}

No presente trabalho focalizamos o discutido problema da origem ou formação das domácias, escolhendo, inicialmente, as principais variedades de Coffea arabica $L$.

$\mathrm{Na}$ revisão da literatura, procuramos nos cingir ùnicamente à bibliografia que trata do assunto em aprêço.

Apreciando convenientemente o problema da origem, duas hipóteses foram aventadas pelos autores para explicar a formação das domácias :

$1 .^{a}$ ) causada por insétos ou por ácaros (LUNDSTRöEM e outros).

2.a) caráter hereditário (CHEVALIER).

Ambas as hipóteses foram consideradas com o objetivo de aclararmos o problema e concluimos, com CHEVALIER, que se trata de um caráter hereditário.

O material constou de sementes, e de ramos com fôlhas de várias idades de cafeeiros que vieram das coleçōes vivas do Instituto Agronômico de Campinas. As observações morfológicas preliminares foram feitas com o auxílio do microscópio estereoscópico. As estruturas anatômicas foram apreciadas em córtes transversais longitudinais, coloridos com violeta-cristal e eritrosina, com espessura de 18 micra.

\section{CONCLUSOES}

1. De um modo geral, as domácias foram observadas nas fôlhas das variedades de Coffea anabica $L$., ocorrendo nas fôlhas novas e adultas, e localizando-se sempre na axila da nervura principal com as secundárias, sendo visíveis em ambas as faces da fôlha. CHESNAIS.

2. Pertencem ao tipo "em fenda" de CHEVALIER E

3. Quanto à origem, concordamos com CHEVALIER, que afirma ser a domácia um caráter morfológico. Para corroborar essa afirmação, tivemos o cuidado de obter plantas de sementes das variedades caturra e bourbon sem contaminação com ácaros e insétos visitadores e pudemos averiguar que tôdas as fôlhas produzidas exibiam domácias.

Do exame microscópico das séries completas de cortes de fôlhas ainda no interior das gêmas observamos que não revelam 
indício algum de domácia. Do minucioso exame morfológico e anatômico de fôlhas de dois tamanhos: $3 \times 7 \mathrm{~mm} \mathrm{e} 4 \times 8 \mathrm{~mm}$ da variedade semperflorens, concluimos que neste estágio, as domácias já se encontram esboçadas, constituindo a primeira fase de sua diferenciação.

\section{SUMARY}

The controversial problem of the domaceae origin is focalized in this paper.

In reviewing the literature, we confined ourselves to the bibliography dealing only with the subject under consideration.

Looking carefully into the problem of their origin, two hypothesis have been poposed to explain the domaceae formation.

$1.0^{\circ}$ ) caused by insects or mites (LUNDSTRÖEM et al.).

$2 .^{\circ}$ ) hereditary character (CHEVALIER).

Both hypothesis were examined toward the enlightenment of this problem and we have concluded, with CHEVALIER, to be an hereditary character.

We worked with coffee seeds and coffee tree branches bearing leaves at varying ages from the live collections belonging to the Instituto Agronômico de Campinas.

The preliminary morphological observations were made with a stereoscopic microscope. The anatomic structures were studied through transversal (cross-section) and longitudinal (lenghtwise) 18 micra cuttings (cuts), dyed with crystal-violet and erythrosine.

\section{AGRADECIMENTOS}

Registramos nossos agradecimentos ao Prof. Dr. Walter Radamés Áccorsi, Catedrático da 3. ${ }^{a}$ Cadeira, pelas sugestões apresentadas durante a realização dêste trabalho.

Somos gratos ao Dr. Alcides Carvalho, Chefe da Secção de Genética do Instituto Agronômico de Campinas, que nos cedeu material das coleções de cafeeiros para nosso estudo.

Nossos reconhecimentos à Fundação Rockfeller, pelos aparelhos concedidos à Cadeira de Botânica da "Luiz de Queiroz", permitindo-nos a elaboração dêste trabalho.

\section{LITERATURA CITADA}

ADAMOLI DE BARROS, MYRTHES A. - 1955 - Contribuição 20 estudo anatômico e morfológico das domácias nas variedades e formas 
de Coffea arabica L. Tése de doutorameno. Piracicaba. - $1959-$ Ocorrência das domácias na família Rubiaceae - Anais E. S. A. «Luiz de Queiroz», 16: 312-337.

CHAMBERLAIN, CHARLES J. - 1932 - Methods In Plants Histology. Fifth Revised Edition. XIV. 416 pp. The University of Chicago. Press. Chicago. Illinois.

CHEVALIER, AUGUSTE \& CHESNAIS, FRANCIS - 1941 - Botanique - Sur les domaties des feuilles de Juglandáceas. Extraido de C. R. Académie des Sciencies 213: 389-392. Séance du lundi 22 septembre. 4 pp. Presc. de M. Louis Bouvier. Paris. - 1941 - Botanique - Nouvelles observation sur les domaties des feuilles das Juglandáceas. Extraido de C. R. Acad. Sc. 213: 596-601. Séänce du lundi 3 novembre. Presc. de M. Hyacinthe Vicent. 5 pp. 13 fig. Paris. - 1947 - Les caféiers du globe, fascicule III: systematique des caféiers et faux-caféiers. (Encyclopédie Biologique, XXVIII) 356 pp. Paul Lechevalier Editeur. Paris.

DU RIETZ, EINAR G., 1930 - On domatia in the Genus Nothofagus. Svensk Botanisk Tidskrift. 24(4): 304-510. 3 figs.

HAMILTON, A. G., 1896 - On domatie in Certain Australian and other Plants. En DU RIETZ, EINAR G.. On domatia in the (ienus Nothofagus. Svensk Botanisk. 24(4): 304-510. 3 figs.

JONHANSEN, DONALD AL.EXANDER, 1940 - Plant microtechnique. New York, Mc(iraw-Hill publications in the botanical sciences) New York and London.

S.AMPAIO, A. J., 1927 - Actuaes difficuldades da Sistematica do Gênero Coffea L. -87 pp. Boletim do Museu Nacional. Rio de Janeiro. 